\title{
Native and microwave-modified Terminalia mantaly gums as sustained-release and bioadhesive excipients in naproxen matrix tablet formulations
}

\author{
Michael Ayodele Odeniyi ${ }^{1, A-F}$, Babatunde Mukhtar Oyedokun ${ }^{1, B-D}$, Oluyemisi Adebowale Bamiro ${ }^{2, C-E}$ \\ 1 Department of Pharmaceutics and Industrial Pharmacy, University of Ibadan, Ibadan, Nigeria \\ ${ }^{2}$ Department of Pharmaceutics and Pharmaceutical Technology, Faculty of Pharmacy, Olabisi Onabanjo University, Sagamu, Nigeria \\ A - research concept and design; B - collection and/or assembly of data; C - data analysis and interpretation; \\ $D$ - writing the article; $E$ - critical revision of the article; $F$ - final approval of article
}

Address for correspondence

Michael Ayodele Odeniyi

E-mail: deleodeniyi@gmail.com

\section{Funding sources}

none declared

\section{Conflict of interest}

none declared

Received on April 11, 2017

Revised on July 06,2017

Accepted on July 24, 2017

\begin{abstract}
Background. Hydrophilic polymers provide a means of sustaining drug delivery. Native gums may be limited in function, but modification may improve their activity.

Objectives. The aim of the study was to evaluate native and modified forms of Terminalia mantaly gum for their sustained-release and bioadhesive properties.

Material and methods. The native gum (NTM) was modified by microwave irradiation for 20 seconds (MTM20) and 60 seconds (MTM60) and characterized using microscopy, Fourier transform infrared spectroscopy (FTIR) and packing properties. The effects of the thermally induced molecular reorientation were determined. Tablet formulations of naproxen were produced by direct compression. The mechanical, bioadhesive and release properties of the formulations were determined.
\end{abstract}

Results. Irradiation of NTM improved the gum's flow properties, resulting in Carr's Index and Hausner's ratios lower than 16\% and 1.25, respectively. Swelling studies showed that MTM20 and MTM60 had lower water absorption capacity and swelling index values, while packing properties improved upon irradiation, as depicted by lower tapped density values. FTIR spectra of samples showed that the irradiated gums were distinct from the native gums and did not interact with naproxen sodium. The gum's mechanical properties improved with MTM20 and MTM60 and sustained-release action of up $12 \mathrm{~h}$ was obtained.

Conclusions. Inclusion of hydroxypropyl methylcellulose (HPMC) in the tablet formulations proved critical for bioadhesion. Microwave irradiation of native Terminalia mantaly gum improved the flow, mechanical and sustained-release properties of Naproxen tablets, and the addition of HPMC increased bioadhesion properties. The tablet properties of the native gum were significantly improved after $20 \mathrm{~s}$ of microwave irradiation.

Key words: sustained-release, microwave irradiation, bioadhesion, Terminalia gum, naproxen sodium

D0I

10.17219/pim/76058

Copyright

○ 2017 by Wroclaw Medical University

This is an article distributed under the terms of the Creative Commons Attribution Non-Commercial License (http://creativecommons.org/licenses/by-nc-nd/4.0/) 
Polymers are becoming increasingly important in the field of drug delivery. The pharmaceutical applications of polymers range from their use as binders in tablets to viscosity- and flow-controlling agents in liquids, suspensions and emulsions. Polymers can also be used as film coatings, to disguise the unpleasant taste of a drug, to enhance drug stability and to modify drug release characteristics. ${ }^{1}$ Plant-based polymers have been studied for their applications in different pharmaceutical dosage forms, such as matrix-controlled systems, buccal films, microspheres, nanoparticles, viscous liquid formulations like ophthalmic solutions, suspensions and implants, and their applicability and efficacy has been proven. Polymers have also been utilized as viscosity enhancers, stabilizers, disintegrants, solubilizers, emulsifiers, suspending agents, gelling agents, bioadhesives and binders. ${ }^{2,3}$

The goal of designing a sustained delivery system is to reduce the frequency of dosing while maintaining uniform drug delivery. Generally, sustained-release dosage forms provide better control of drug levels in plasma, reduce dosage frequency and increase therapeutic efficacy through steady drug delivery. ${ }^{4}$

The bioadhesive property of certain polymeric systems has found relevance in drug delivery as a means of prolonging contact time in the various mucosal routes of drug administration. The ability to maintain a delivery system at a particular location for an extended period of time has great appeal for local action as well as systemic drug bioavailability. ${ }^{5}$ Natural gums have been found to be biocompatible and non-irritating, and they possess excellent binding and bioadhesive properties. ${ }^{6}$ However, there may be a need to modify these gums in order to achieve the desired formulation effects. Microwave irradiation has provided a convenient means of modifying polymers by reducing processing time. ${ }^{7,8}$ While a few gums have been modified by grafting functional groups through microwave irradiation, ${ }^{9,10}$ the present work seeks to determine the effect of duration of irradiation on the mechanical properties, bioadhesion characteristics and sustained-release properties of a new plant gum from the Terminalia mantaly tree in a directly compressed matrix tablet.

Terminalia is a genus of large trees of the flowering plant family Combretaceae, comprising around 100 species distributed in tropical regions of the world. Naproxen, the candidate drug, is a non-steroidal anti-inflammatory drug of the propionic acid class that relieves pain, fever, swelling and stiffness. A sustained-release form will be useful in treating rheumatoid arthritis, osteoarthritis and ankylosing spondylitis.

\section{Material and methods}

The materials used include naproxen sodium, which was received as a gift from Swiss Pharma Nigeria Ltd.
(Lagos, Nigeria); Terminalia gum, extracted from a Terminalia mantaly tree trunk located at the Botanical Gardens, University of Ibadan, Nigeria; hydroxypropyl methyl cellulose (HPMC) (Colorcon Asia Limited, Mumbai, India); microcrystalline mellulose (Aqualon Group, Hercules Inc., Wilmington, DE, USA); Aerosil ${ }^{\circledR} 200$ (Evonik Degussa Corp., Essen Germany); magnesium stearate (R\&M Chemicals, Essex, UK). Other reagents were of analytical grade.

\section{Preparation of the gum}

The plant sample was initially identified and authenticated at the University of Ibadan Herbarium (voucher number UIH-22529). The gum was purified using previously described methods. ${ }^{11,12}$ Briefly, the exudate was hydrated in a $0.5: 95.5(\mathrm{v} / \mathrm{v}) \mathrm{CHCl}_{3} /$ water mixture for five days with intermittent stirring; extraneous materials were removed by straining through a muslin cloth. Absolute ethanol was used to precipitate the gum from the solution. The precipitated gum was filtered, washed with diethyl ether, and then dried in a hot air oven at $40^{\circ} \mathrm{C}$ for 18 hours. The resultant pure gum was pulverized using a laboratory blender, sieved, and stored in an airtight container.

\section{Modification of the Terminalia gum by microwave irradiation}

A $40 \mathrm{~g}$ quantity of the native gum was made into a slurry with distilled water. The slurry was dried in divided quantities on square ceramic tiles with the aid of a $2450 \mathrm{MHz}$ microwave unit (Model R-218L, Sharp Corp., Sakai, Japan) which released 800 watts of heat energy for 20 seconds (MTM20) and 60 seconds (MTM60). The microwave irradiated samples were subsequently dried in an oven set at $60^{\circ} \mathrm{C}$ for 24 hours. The dried gums were scraped off the tiles and milled using a laboratory blender. The powder was passed through a sieve (mesh size 120) to obtain uniform sized particles.

\section{Interactions between Terminalia gum and naproxen sodium}

Fourier transform infrared spectroscopy (FTIR) spectra were obtained for the pure gum and naproxen sodium samples, and for 1: 1 mixtures of each gum sample and naproxen sodium, in order to determine if interactions occurred between the gums and the active ingredient. Each sample powder $(1.0 \mathrm{mg})$ was finely ground to about $2.0 \mu \mathrm{m}$ in size and mixed with approximately $100 \mathrm{mg}$ of dry potassium bromide (KBr). Each sample was analyzed in a Spectrum RX-1 Fourier Transform Infrared Spectrometer (Perkin Elmer Ltd., Beaconsfield, UK). 


\section{Formulation design for naproxen sodium matrix tablets}

The formulation design utilized in the manufacture of the naproxen matrix tablets used in this study is given in Table 1. Twelve batches (F1-F12) of naproxen tablets were prepared. F1-F4 contain NTM, F5-F8 contain MTM20, while F9-F12 contain MTM60.

\section{Preparation of matrix tablets}

Matrix tablets were produced by weighing, screening and mixing the excipients through a 40-mesh sieve, then adding the active ingredient and mixing thoroughly. The bulk density and tapped density of the powder blend was determined with graduated cylinders according to USP guidelines. The powders were compressed using a tableting machine (Manesty Machines Ltd., Liverpool, England) fitted with round concave-faced $10 \mathrm{~mm}$ diameter punches and dies. The compression force was 1 metric ton.

\section{Evaluation of the tablets}

Twenty tablets were randomly selected from each batch and the average weight of the tablets was determined. Tablet thickness was measured for all tablets in each batch using a micrometer screw gauge. The crushing strength of the tablets was determined at room temperature by diametral compression ${ }^{13}$ using a hardness tester (Model EH 01, Copley Scientific, Mumbai, India). The results were taken only from tablets which split cleanly into two halves without any sign of lamination. The determinations were done in triplicate and the mean was calculated as the crushing strength.

\section{Determination of ex vivo mucoadhesive strength}

In determining the ex vivo mucoadhesive strength of the formulations, a segment of the intestine of a freshly sacrificed cow was fixed, using an elastic rubber band, onto a stainless steel cylinder with the basolateral side facing the cylinder. ${ }^{14}$ Tablets containing different concentrations of the gum were pressed on the apical side and the cylinder was placed into $500 \mathrm{~mL}$ of a $\mathrm{pH} 6.8$ buffer medium. The rotation speed was set at $50 \mathrm{rpm}$. The elapsed time for the tablet to detach from the mucosa was observed and recorded. ${ }^{15}$

\section{Drug release}

The in vitro drug dissolution study was carried out in $900 \mathrm{~mL}$ of $0.1 \mathrm{M} \mathrm{HCl}$ at $37.0 \pm 0.5^{\circ} \mathrm{C}$ for the first hour and in $\mathrm{pH} 6.8$ phosphate buffer for $11 \mathrm{~h}$ (mimicking drug release within the intestine), using the USP basket method at a stirring speed of $100 \mathrm{rpm}$. Samples were withdrawn at predetermined intervals and immediately replaced with an equal volume of fresh dissolution medium. The samples were filtered using a $0.45 \mu \mathrm{m}$ membrane filter and the amount of drug released was determined using a UV spectrophotometer (Hitachi U2000, Tokyo, Japan) at $231 \mathrm{~nm}$.

\section{Mechanism of drug release}

The mechanism of drug release from the matrix tablets was determined by fitting data into different release models as previously described. ${ }^{16}$ Further, the mean dissolution time (MDT) - a more accurate method for assessing drug release rate than $t_{x} \%$ - was obtained by fitting the dissolution data into the equation:

$$
\operatorname{MDT}=(\mathrm{n} / \mathrm{n}+1) \mathrm{k}^{-1 / \mathrm{n}}
$$

where $\mathrm{n}$ is the release exponent and $\mathrm{k}$ is release rate constant. ${ }^{17}$ A higher MDT value indicates that the polymer has a higher drug retaining ability. ${ }^{18}$ The drug retarding efficiency and release rate can be obtained from the equation. Further, the Akaike criterion index (AIC) was used to determine the most suitable model using DDSolver, an add-in program for Microsoft Excel. ${ }^{19}$

\section{Statistical analysis}

The statistical analysis was carried out using Students' t-test and ANOVA, with $\mathrm{p} \leq 0.05$ considered significant.

Table 1. Formulation design for naproxen sodium matrix tablets

\begin{tabular}{|c|c|c|c|c|c|c|c|c|c|c|c|c|}
\hline \multirow{2}{*}{ Ingredient (mg) } & \multicolumn{4}{|c|}{ Native gum } & \multicolumn{4}{|c|}{ Irradiated gum (20 s) } & \multicolumn{4}{|c|}{ Irradiated gum (60 s) } \\
\hline & $\mathrm{F} 1$ & $\mathrm{~F} 2$ & F3 & $\mathrm{F} 4$ & $\mathrm{~F} 5$ & F6 & F7 & F8 & F9 & $\mathrm{F} 10$ & F11 & F12 \\
\hline Naproxen $\mathrm{Na}^{+}$ & 200 & 200 & 200 & 200 & 200 & 200 & 200 & 200 & 200 & 200 & 200 & 200 \\
\hline Terminalia gum & 20 & 40 & 60 & 40 & 20 & 40 & 60 & 40 & 20 & 40 & 60 & 40 \\
\hline HPMC & 10 & 10 & 10 & - & 20 & 20 & 20 & - & 30 & 30 & 30 & - \\
\hline MCC & 166 & 146 & 126 & 156 & 156 & 136 & 116 & 156 & 146 & 126 & 106 & 156 \\
\hline Aerosil & 2 & 2 & 2 & 2 & 2 & 2 & 2 & 2 & 2 & 2 & 2 & 2 \\
\hline Magnesium stearate & 2 & 2 & 2 & 2 & 2 & 2 & 2 & 2 & 2 & 2 & 2 & 2 \\
\hline Total (mg) & 400 & 400 & 400 & 400 & 400 & 400 & 400 & 400 & 400 & 400 & 400 & 400 \\
\hline
\end{tabular}




\section{Results and discussion}

\section{Physicochemical properties of the gum samples}

The presence of any interaction between the drug and excipient was evaluated using the FTIR spectroscopy method. The FTIR spectra of the pure drug, pure gum and gum-drug physical mixtures were measured. The major peaks observed for the pure samples remained discernible (Fig. 1) in the gum-drug mixtures. This means that little or no interaction occurred between the polymers and naproxen sodium.

The micromeritic properties of the formulations are given in Table 2. There were no significant differences in the bulk and tapped densities of the formulations. The angle of repose obtained for the formulation blends was above $40^{\circ}$, indicating uneven flow.

The flow properties of a powder are essential for determining its suitability as direct compression excipients. ${ }^{20}$ Flow properties were determined by Hausner's ratio, Carr's index and the angle of repose (Table 3). The results obtained for Carr's index were 35\% for NTM, 10.67\% for MTM20 and $13.79 \%$ for MTM60. The greatly reduced values (less than 16\%) for the microwaved gums indicated a significant improvement in flow properties compared to the native gum, which tended towards cohesiveness at 35\%. The Hausner's ratios were 1.54 (NTM), 1.12 (MTM20) and 1.16 (MTM60). Both values for the irradiated gums were less than 1.25, indicating good flow. The native gum, however, had a value greater than 1.25 , sug-
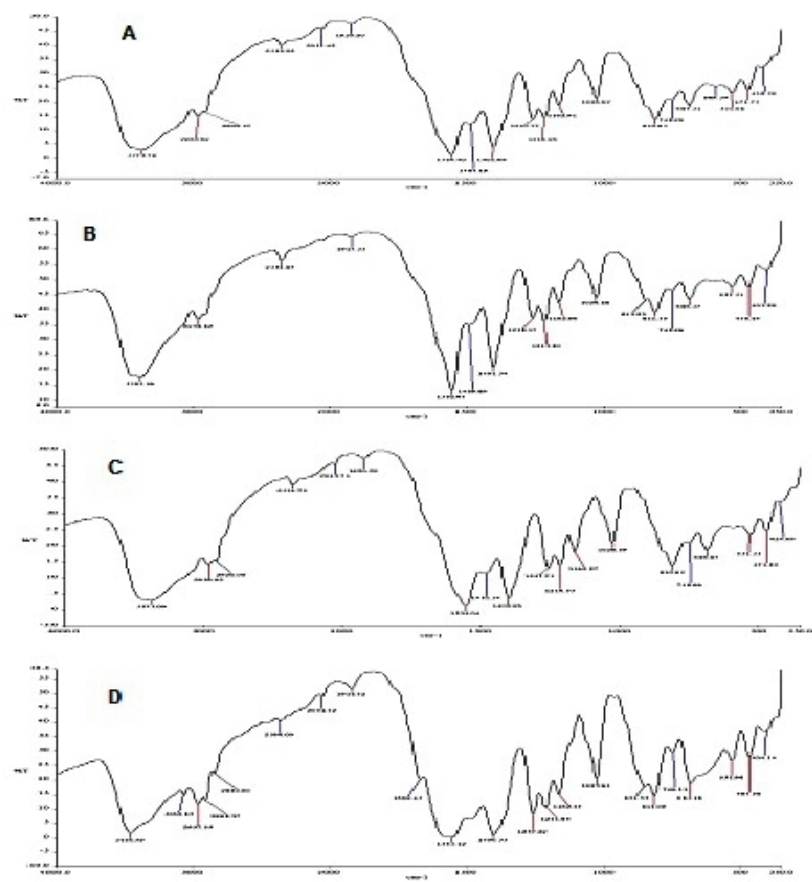

Fig. 1. FTIR spectra of $1: 1$ physical mixtures of $(A)$ native gum with naproxen; (B) microwaved gum with naproxen (MTM20); (C) microwaved gum with naproxen (MTM60); and (D) pure naproxen sodium
Table 2. Density measurements and flow properties of formulation blends

\begin{tabular}{|c|c|c|c|}
\hline Blends & $\begin{array}{c}\text { Bulk density } \\
\left(\mathrm{g} / \mathrm{cm}^{3}\right)\end{array}$ & $\begin{array}{c}\text { Tapped density } \\
\left(\mathrm{g} / \mathrm{cm}^{3}\right)\end{array}$ & $\begin{array}{c}\text { Angle of repose } \\
\left({ }^{\circ}\right)\end{array}$ \\
\hline F1 & 0.168 & 0.200 & 55.4 \\
F2 & 0.159 & 0.199 & 53.6 \\
F3 & 0.177 & 0.193 & 52.9 \\
F4 & 0.182 & 0.205 & 51.5 \\
F5 & 0.177 & 0.201 & 50.8 \\
F6 & 0.174 & 0.207 & 51.5 \\
F7 & 0.176 & 0.224 & 53.6 \\
F8 & 0.171 & 0.199 & 52.2 \\
F9 & 0.159 & 0.187 & 54.2 \\
F10 & 0.171 & 0.199 & 55.4 \\
F11 & 0.163 & 0.199 & 54.2 \\
F12 & 0.161 & 0.199 & 54.2 \\
\hline
\end{tabular}

gesting that irradiation of native Terminalia mantaly gum significantly improves its flow. There were no significant differences in the angles of repose observed for Terminalia mantaly gum samples. The ranking was in the following order: MTM20 $\left(58.9^{\circ}\right)>\operatorname{MTM} 60\left(58.74^{\circ}\right)>$ NTM $\left(57.8^{\circ}\right)$. The values were observed to be slightly higher for the irradiated gums. However, all values were higher than $40^{\circ}$ but lower than $60^{\circ}$, indicating uneven flow.

Particle size influences the flow properties of powders; the greater the particle size, the greater the ease of flow. There was a progressive increase in the particle size of the gums as the duration of exposure to microwave irradiation increased. The increase in size is likely due to swelling of the gum particles upon the addition of water during mucilage formation, prior to irradiation. The average particle diameter of MTM60 $(1316.22 \mu \mathrm{m})$ was five times that of the average NTM particle diameter $(263.10 \mu \mathrm{m})$, while the average particle diameter of MTM20 $(696.78 \mu \mathrm{m})$ was more than twice the average particle diameter of NTM (Table 3). Although the angles of repose observed for the gum samples showed only slight differences, the increased particle sizes of the microwaved gums indicates better flow. The ranking of the ease of flow was MTM60 > MTM20 > NTM.

Table 3. Physicochemical properties of Terminalia mantaly gum

\begin{tabular}{|l|c|c|c|}
\multicolumn{1}{c|}{ Parameters } & $\begin{array}{c}\text { Native } \\
\text { gum }\end{array}$ & $\begin{array}{c}\text { Microwaved } \\
\text { gum (20 s) }\end{array}$ & $\begin{array}{c}\text { Microwaved } \\
\text { gum (60 s) }\end{array}$ \\
\hline Particle diameter $(\mu \mathrm{m})$ & 263.10 & 696.78 & 1316.22 \\
Angle of repose $\left(^{\circ}\right)$ & 57.80 & 58.09 & 58.74 \\
Particle density $\left(\mathrm{g} / \mathrm{cm}^{3}\right)$ & 1.32 & 1.22 & 1.29 \\
Bulk density $\left(\mathrm{g} / \mathrm{cm}^{3}\right)$ & 0.090 & 0.092 & 0.10 \\
Tapped density $\left(\mathrm{g} / \mathrm{cm}^{3}\right)$ & 0.139 & 0.103 & 0.116 \\
Hausner's ratio & 1.54 & 1.12 & 1.16 \\
Carr's index & 35 & 10.67 & 13.79 \\
Swelling index & 8.4 & 7.2 & 7.6 \\
Water absorption capacity & 10.71 & 9.20 & 9.61 \\
pH & 7.31 & 5.37 & 6.22 \\
\hline
\end{tabular}




\section{Evaluation of naproxen tablet formulations}

All the matrix tablets were evaluated for their physical, mechanical and release properties. The tablets produced from the powder blends had uniform thickness, low friability and a high degree of weight uniformity (Table 4). It is important to ensure that tablets in each batch of formulation fall within the appropriate size range, as this will affect chemical content. ${ }^{21}$ The British Pharmacopoeia states that for tablets having mean weights of greater than $250 \mathrm{mg}$, no more than two tablets are permitted to deviate from the mean by greater than $\pm 5 \%$ and no tablet should deviate by more than $\pm 10 \%$. The results obtained (Table 4 ) shows that the highest deviation observed was $0.02 \%$. Thus, all the matrix tablet batches were satisfactory in this regard. Generally, excessive weight variation is attributable to poor granule flow during compression, improper die filling or the presence of air in the powder/granule bed. ${ }^{21}$

Crushing strength provides a measure of tablet strength, while friability is a measure of tablet weakness. ${ }^{22}$ In this study, the highest crushing strength was observed with MTM60 (40.41 N, tablet F9), followed by MTM20 (35.40 N, tablet F6) and NTM (21.43 N, tablet F2). Matrix tablets F9, F6 and F2 contained $40 \mathrm{mg}$ (10\%) of the gum samples. Further, comparison can be made between the crushing strengths of matrix tablet batches containing the same concentrations of the gum samples. Tablets F1 $(13.44 \mathrm{~N}), \mathrm{F} 5(16.23 \mathrm{~N})$ and F9 $(23.19 \mathrm{~N})$ contained $20 \mathrm{mg}$ (5\%) of NTM, MTM20 and MTM60, respectively. It is also noteworthy that tablets F1, F5 and F9 contain $10 \mathrm{mg}$, $20 \mathrm{mg}$ and $30 \mathrm{mg}$ of HPMC, respectively (Table 4).

Table 4 also clearly shows that crushing strength increased as the gum and HPMC concentrations increased, resulting in the ranking MTM60 > MTM $20>$ NTM. It can also be seen that there was a marked reduction in the crushing strengths of matrix tablets F4, F8 and F12, which shows that the exclusion of HPMC resulted in tablets with low mechanical strength.
Friability is a disruptive force used to evaluate the ability of tablets to withstand chipping and breakage during use. A maximum weight loss of $1 \%$ is usually acceptable for tablets. ${ }^{23}$ Table 3 shows friability results ranging from $1.87 \%$ (tablet F11) to $4.09 \%$ (tablet F8). The failure to meet the specifications of the friability test may be due to low binder concentration, resulting in loose interparticulate bonding, or the use of low compression pressure in the tablet machine. ${ }^{21}$ Thus, the binder concentrations and compression pressure of 0.5 metric tons used for this study might be sub-optimal for formulating tablets which satisfy specifications for friability.

The crushing strength/friability ratio (CSFR) provides a measure of tablet strength and weakness. CSFR has been described as a useful index for tablet quality. ${ }^{12}$ Also, Bamiro et al. reported that the higher the value of this index, the stronger the tablet. ${ }^{24}$ The results obtained (Table 4) generally showed an increase in CSFR and hence, tablet strength, as binder and HPMC concentrations increased. Higher CSFR values were noted for tablets F9, F10 and F11, which all contain MTM60. The ranking was in the order MTM60 > MTM20 > NTM. The lowest values were obtained for matrix tablets F4, F8 and F12, none of which contain HPMC. These findings are consistent with deductions made from the crushing strength results, which suggests that while binding activity is greater with MTM60 and MTM20 relative to NTM, the inclusion of HPMC increases tablet strength.

\section{Release studies on naproxen tablet formulations}

Tablet disintegration has been described as the net outcome of adhesive and disintegrating forces that are activated when a tablet is subjected to an aqueous environment. Disintegration time is usually a necessary step for dissolution, and it could be the rate-determining step in the process of drug absorption. ${ }^{25}$ This is because a drug entity must be present in solution before it can be absorbed, and this requires an initial disintegration process.

Table 4. Mechanical properties of naproxen matrix tablets

\begin{tabular}{|c|c|c|c|c|c|}
\hline Tablet batches & $\begin{array}{l}\text { Weight uniformity } \\
\qquad(\mathrm{mg})\end{array}$ & $\begin{array}{l}\text { Thickness } \\
(\mathrm{mm})\end{array}$ & $\begin{array}{l}\text { Crushing strength } \\
(\mathrm{N})\end{array}$ & $\begin{array}{l}\text { Friability } \\
\qquad(\%)\end{array}$ & $\begin{array}{l}\text { Crushing strength/ } \\
\text { Friability ratio (CSFR) }\end{array}$ \\
\hline F1 & $0.39 \pm 0.01$ & $3.59 \pm 0.12$ & $13.44 \pm 3.74$ & $2.22 \pm 0.01$ & 6.05 \\
\hline $\mathrm{F} 2$ & $0.41 \pm 0.01$ & $3.76 \pm 0.18$ & $21.43 \pm 11.30$ & $2.70 \pm 0.04$ & 7.94 \\
\hline F3 & $0.40 \pm 0.02$ & $3.75 \pm 0.26$ & $16.18 \pm 0.00$ & $2.24 \pm 0.11$ & 7.22 \\
\hline $\mathrm{F} 4$ & $0.39 \pm 0.02$ & $3.60 \pm 0.17$ & $15.84 \pm 0.00$ & $2.59 \pm 0.02$ & 6.12 \\
\hline F5 & $0.41 \pm 0.02$ & $3.71 \pm 0.17$ & $16.23 \pm 0.55$ & $1.95 \pm 0.01$ & 8.32 \\
\hline F6 & $0.41 \pm 0.01$ & $3.76 \pm 0.13$ & $35.40 \pm 0.07$ & $2.25 \pm 0.05$ & 15.73 \\
\hline F7 & $0.39 \pm 0.01$ & $3.64 \pm 0.12$ & $27.78 \pm 14.59$ & $3.16 \pm 0.13$ & 8.79 \\
\hline F8 & $0.40 \pm 0.01$ & $3.68 \pm 0.13$ & $14.96 \pm 4.86$ & $4.09 \pm 0.02$ & 3.66 \\
\hline F9 & $0.40 \pm 0.01$ & $3.72 \pm 0.12$ & $23.19 \pm 5.06$ & $2.81 \pm 0.03$ & 8.25 \\
\hline F10 & $0.40 \pm 0.01$ & $3.72 \pm 0.11$ & $40.41 \pm 2.49$ & $2.16 \pm 0.01$ & 18.71 \\
\hline F11 & $0.41 \pm 0.01$ & $3.65 \pm 0.07$ & $29.68 \pm 0.00$ & $1.87 \pm 0.04$ & 12.66 \\
\hline F12 & $0.41 \pm 0.01$ & $3.67 \pm 0.08$ & $16.77 \pm 8.11$ & $2.31 \pm 0.12$ & 7.26 \\
\hline
\end{tabular}


Among the tablets incorporating HPMC, disintegration time decreased as polymer concentration increased, regardless of increases in HPMC concentration. Thus, for tablet batches containing NTM, MTM20 and MTM60, the longest disintegration time was observed at the lowest polymer concentration of $5 \%$ (20 mg). This suggests that as polymer concentration increased, the swelling and erosion rates of the tablets increased.

Generally, the matrix tablets containing NTM had the longest disintegration times - not less than 3 hours - and thus appear to be most suitable for sustained-release action. The ranking was NTM > MTM20 > MTM60. For the tablets containing no HPMC, the ranking was MTM20 > NTM > MTM60. Hence, in the absence of HPMC, MTM20 had the best sustained-release action.

The crushing strength-friability/disintegration time ratio (CSFR/DT) is a good index of tablet quality because it measures tablet strength (CS) and weakness (friability), which are indicators of the bond strength; and simultaneously evaluates any negative effect of these parameters on disintegration time, which is an indicator of bond disruption. A high CSFR/DT value indicates a good balance between binding and disintegration properties. Generally, the higher the CSFR/DT values, the better the disintegration of the tablet. ${ }^{26}$

Matrix tablets F2, F6 and F10, which contained $40 \mathrm{mg}$ of gum polymer, were found to possess the highest CSFR/DT values. CSFR/DT values also increased as the proportions of HPMC increased (Table 5). Matrix tablets F4, F8 and F12, containing HPMC, had the lowest CSFR/DT values. The ranking was generally MTM20 > MTM60 > NTM.

Bioadhesion times were studied for all the matrix tablets. It was generally observed that matrix tablets F4, F8 and F12 (which did not contain HPMC) had the poorest adhesion strength as shown by their short bioadhesion times (Table 5). Thus, the inclusion of HPMC improved bioadhesion. Among the matrix tablets containing

Table 5. Disintegration and bioadhesion times for naproxen matrix tablets (mean $\pm s d, n=3$ )

\begin{tabular}{|c|c|c|c|} 
Formulations & $\begin{array}{c}\text { Disintegration } \\
\text { time (hr) }\end{array}$ & $\begin{array}{c}\text { Crushing strength - } \\
\text { friability/disintegration } \\
\text { time ratio (CSFR/DT) }\end{array}$ & $\begin{array}{c}\text { Bioadhesion } \\
\text { time (mins) }\end{array}$ \\
F1 & $3.53 \pm 0.51$ & 1.71 & $13.05 \pm 1.05$ \\
F2 & $3.42 \pm 0.35$ & 2.32 & $49.22 \pm 3.11$ \\
F3 & $3.08 \pm 0.09$ & 2.34 & $16.14 \pm 2.20$ \\
F4 & $2.58 \pm 0.17$ & 2.37 & $5.06 \pm 0.09$ \\
F5 & $3.17 \pm 0.05$ & 2.62 & $20.01 \pm 2.01$ \\
F6 & $2.13 \pm 0.42$ & 7.30 & $21.15 \pm 4.50$ \\
F7 & $2.00 \pm 0.16$ & 4.40 & $16.18 \pm 1.01$ \\
F8 & $2.70 \pm 0.11$ & 1.36 & $8.05 \pm 2.08$ \\
F9 & $2.53 \pm 0.28$ & 3.26 & $11.00 \pm 1.15$ \\
F10 & $1.27 \pm 0.16$ & 14.73 & $12.15 \pm 2.25$ \\
F11 & $2.18 \pm 0.63$ & 5.81 & $18.58 \pm 1.06$ \\
F12 & $2.33 \pm 0.44$ & 3.12 & $4.06 \pm 0.05$ \\
\hline
\end{tabular}

Table 6. Model independent dissolution parameters for naproxen matrix tablets

\begin{tabular}{|c|c|c|c|}
\hline Formulations & $\begin{array}{c}\text { Disintegration } \\
\text { time (hr) }\end{array}$ & $\begin{array}{c}\text { Crushing strength - } \\
\text { friability/disintegration } \\
\text { time ratio (CSFR/DT) }\end{array}$ & $\begin{array}{c}\text { Bioadhesion } \\
\text { time (mins) }\end{array}$ \\
\hline F1 & $3.53 \pm 0.51$ & 1.71 & $13.05 \pm 1.05$ \\
F2 & $3.42 \pm 0.35$ & 2.32 & $49.22 \pm 3.11$ \\
F3 & $3.08 \pm 0.09$ & 2.34 & $16.14 \pm 2.20$ \\
F4 & $2.58 \pm 0.17$ & 2.37 & $5.06 \pm 0.09$ \\
F5 & $3.17 \pm 0.05$ & 2.62 & $20.01 \pm 2.01$ \\
F6 & $2.13 \pm 0.42$ & 7.30 & $21.15 \pm 4.50$ \\
F7 & $2.00 \pm 0.16$ & 4.40 & $16.18 \pm 1.01$ \\
F8 & $2.70 \pm 0.11$ & 1.36 & $8.05 \pm 2.08$ \\
F9 & $2.53 \pm 0.28$ & 3.26 & $11.00 \pm 1.15$ \\
F10 & $1.27 \pm 0.16$ & 14.73 & $12.15 \pm 2.25$ \\
F11 & $2.18 \pm 0.63$ & 5.81 & $18.58 \pm 1.06$ \\
F12 & $2.33 \pm 0.44$ & 3.12 & $4.06 \pm 0.05$ \\
\hline
\end{tabular}

HPMC, the longest bioadhesion time occurred with tablet F2. The proportion of NTM and HPMC in tablet F2 appear to be the optimum for achieving longer bioadhesion (assuming uniform attachment force). The shortest bioadhesion time was 11 min (tablet F9).

It was observed that as polymer concentration increased (from 5 to 10\%) across F1-F2, F5-F6 and F9-F10, bioadhesion times increased correspondingly. However, a further increase in polymer concentration to $15 \%$ in tablets F3, F7 and F11 led to shorter bioadhesion times than observed at $10 \%$, which suggests that bioadhesion is reduced in the presence of HPMC beyond a polymer concentration of $10 \%$. Generally, the tablets containing MTM20 showed longer bioadhesion times relative to tablets containing MTM60. The ranking was NTM > MTM20 > MTM60.

Dissolution parameters were obtained for all the matrix tablet batches in $0.1 \mathrm{M} \mathrm{HCl}$ and $\mathrm{pH} 6.8$ phosphate buffer solutions. The tablets were first evaluated in the $0.1 \mathrm{M} \mathrm{HCl}$ buffer for the first hour before being immersed in the pH 6.8 phosphate buffer for 11 subsequent hours. The percentage drug release in HCL buffer was negligible for all the matrix tablet batches, with the major part of the drug being released in the phosphate buffer. This might suggest suitability for targeted delivery within the intestinal lumen.

As noted above, matrix tablets $\mathrm{F} 1-\mathrm{F} 4$ contained native Terminalia gum, while tablets F5-F8 and F9-F12 contained gum irradiated for $20 \mathrm{~s}$ and $60 \mathrm{~s}$, respectively. Matrix tablets containing native gum (F1-F4) generally had the lowest percentage of drug release. The release rate was found to increase with irradiation time for the microwave-modified gum samples. This can be explained by the observed increase in particle diameter and surface area of the gum particles after exposure to irradiation (Table 3), resulting in better solvent uptake and swelling.

Generally lower percentage drug release rates were observed for matrix tablets which did not contain HPMC: F4, 
Table 7. In vitro release kinetics for naproxen matrix tablet formulations

\begin{tabular}{|c|c|c|c|c|c|c|c|c|c|c|c|c|}
\hline \multirow{2}{*}{$\begin{array}{l}\text { Formulation } \\
\text { code }\end{array}$} & \multicolumn{2}{|c|}{ Zero-order } & \multicolumn{2}{|c|}{ First-order } & \multicolumn{2}{|c|}{ Higuchi } & \multicolumn{2}{|c|}{ Hixson-Crowell } & \multicolumn{3}{|c|}{ Korsemeyer-Peppas } & \multirow{2}{*}{ AIC } \\
\hline & $r^{2}$ & $\mathrm{k}_{0}$ & $r^{2}$ & $\mathrm{k}_{1}$ & $r^{2}$ & $\mathrm{~K}_{\mathrm{H}}$ & $r^{2}$ & $\mathrm{~K}_{\mathrm{HC}}$ & $\mathrm{N}$ & $r^{2}$ & K & \\
\hline F1 & 0.965 & 0.117 & 0.947 & 0.002 & 0.831 & 2.139 & 0.955 & 0.000 & 1.132 & 0.966 & 0.053 & 78.01 \\
\hline$F 2$ & 0.970 & 0.115 & 0.952 & 0.001 & 0.838 & 2.101 & 0.960 & 0.000 & 1.117 & 0.970 & 0.057 & 75.23 \\
\hline F3 & 0.967 & 0.111 & 0.951 & 0.001 & 0.839 & 2.043 & 0.958 & 0.000 & 1.117 & 0.968 & 0.056 & 75.03 \\
\hline F4 & 0.958 & 0.065 & 0.964 & 0.001 & 0.901 & 1.203 & 0.963 & 0.000 & 0.841 & 0.963 & 0.166 & 60.19 \\
\hline F5 & 0.957 & 0.127 & 0.970 & 0.002 & 0.901 & 2.374 & 0.968 & 0.001 & 0.828 & 0.963 & 0.353 & 79.74 \\
\hline F6 & 0.962 & 0.134 & 0.970 & 0.002 & 0.910 & 2.504 & 0.970 & 0.000 & 0.823 & 0.969 & 0.383 & 78.17 \\
\hline F7 & 0.967 & 0.099 & 0.964 & 0.001 & 0.867 & 1.821 & 0.966 & 0.000 & 0.978 & 0.964 & 0.112 & 70.79 \\
\hline F8 & 0.961 & 0.046 & 0.958 & 0.001 & 0.859 & 0.846 & 0.959 & 0.001 & 1.029 & 0.958 & 0.039 & 50.08 \\
\hline F9 & 0.984 & 0.124 & 0.965 & 0.002 & 0.857 & 2.284 & 0.973 & 0.000 & 1.095 & 0.984 & 0.071 & 67.86 \\
\hline F10 & 0.969 & 0.152 & 0.964 & 0.002 & 0.884 & 2.822 & 0.969 & 0.000 & 0.919 & 0.969 & 0.246 & 81.99 \\
\hline F11 & 0.977 & 0.138 & 0.970 & 0.002 & 0.878 & 2.541 & 0.975 & 0.000 & 0.963 & 0.976 & 0.171 & 75.22 \\
\hline F12 & 0.985 & 0.077 & 0.985 & 0.001 & 0.887 & 1.421 & 0.986 & 0.000 & 0.961 & 0.984 & 0.097 & 53.00 \\
\hline
\end{tabular}

AIC - Akaike Information Criterion.

F8 and F12, at 31.2, 21.73 and 37.61\%, respectively. This can be attributed to the absence of the disintegrant action of HPMC, allowing for more sustained-release effects.

All the matrix tablets containing NTM (F1-F4) had values lower than $60 \%$. There was no marked change in drug release as the polymer concentration increased from 5 to $10 \%$ ( 57.43 and $54.97 \%$ for F1 and F2, respectively). However, peak release was observed at a polymer concentration of $10 \%$ for matrix tablets F6 (65.36\%) and F10 (74.64\%). F10 represents the highest percentage drug release observed for all the matrix tablets. The percentage drug release was found to increase in the order MTM60 > MTM20 > NTM.

Table 7 shows the release parameters (correlation coefficient $\left[r^{2}\right]$, diffusional release exponents $[n]$ and kinetic constants) of matrix tablets F1-F12, obtained using zero order, first order, Higuchi, Hixson-Crowell and Korsemeyer release models. With the exception of the Higuchi model, all the models exhibited the greatest correlation values with the F12 matrix tablets. The highest correlation coefficient (0.986) was observed in the Hixson-Crowell model. The zero and first-order models both have $\mathrm{r}^{2}$ values of 0.985 , while the Korsemeyer-Peppas model showed 0.984 . The highest $r^{2}$ value observed for the Higuchi model (0.910) occurred with F6 matrix tablets.

Matrix tablets F4, F5 and F6 had release exponent (n) values $<0.89$ but $>0.45$; thus indicating Non-Fickian transport. All the other matrix tablets exhibited $n$ values $>0.89$, indicating Super Case II transport. This indicates a combination of diffusion and erosion-controlled drug release. ${ }^{16}$

Table 6 shows the model-independent release parameters. The longest drug release times were observed with matrix tablets F4, F8 and F12, none of which contain HPMC, but which contain 10\% (40 mg) of NTM, MTM20 and MTM60, respectively. There were no significant differences in $t_{25 \%}, t_{50 \%}, t_{75 \%}$ and $t_{90 \%}$ drug release between tablets F1-F3, F5-F7 or F9-F11.
Sustained-release action was strongest in the formulations containing MTM20, and this action was more pronounced in formulations F4, F8 and F12, which did not contain HPMC. The $t_{90 \%}$ values were $29.78 \mathrm{~h}, 32.82 \mathrm{~h}$ and $19.50 \mathrm{~h}$ for F4, F8 and F12, respectively. Ranking for sustained-release action was in the order MTM20 > NTM > MTM60. There were no significant differences in MDT for any of the gum samples/matrix tablets.

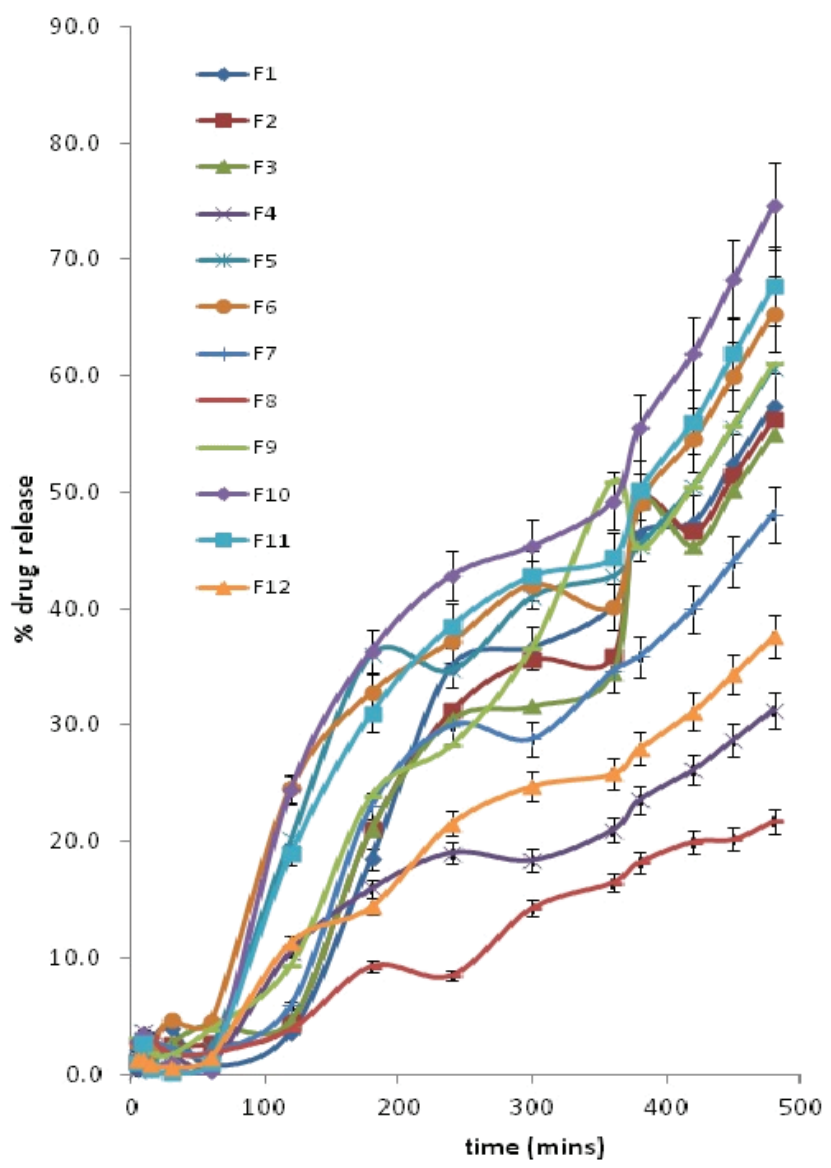

Fig. 2. Drug release profiles from naproxen matrix tablets 


\section{Conclusion}

The flow properties of Terminalia gum were improved by microwave irradiation. Irradiation of native Terminalia gum for 20 seconds caused an improvement in its sustainedrelease activity. Bioadhesion improved with increasing polymer concentrations in formulations containing both Terminalia gum and HPMC. Irradiation of Terminalia gum generally improves its disintegrant action. A blend of the gum and HPMC could be directly compressed to give a simple, fast and consistent method of tablet production.

\section{References}

1. Nimish S, Mewada RK, Tejal S. Application of biodegradable polymers in controlled drug delivery. Institute of Technology, Nirma University, Ahmedabad. 2011;382(481):8-10.

2. Pandey R, Khuller GK. Polymer based drug delivery systems for mycobacterial infections. Curr Drug Deliv. 2004;1:195-201.

3. Chamarthy SP, Pinal R. Plasticizer concentration and the performance of a diffusion-controlled polymeric drug delivery system. Colloids Surf. A. Physiochem Eng Asp. 2008;331:25-30.

4. Roy H, Brahma CK, Nandi S, Parida KR. Formulation and design of sustained release matrix tablets of metformin hydrochloride: Influence of hypromellose and polyacrylate polymers. Int J Applied Basic Med Res. 2013;3:55-63. doi. 10.4103/2229-516X.112242.

5. Sharma BR, Kumar V, Soni P. Ceric ammonium nitrate initiated graft copolymerization of acrylamide onto Cassia tora gum. J Appl Polym Sci. 2002;86:3250-3255.

6. Odeniyi MA, Babalola AO, Ayorinde JO. Evaluation of Cedrela gum as a binder and bioadhesive component in ibuprofen tablet formulations. Braz J Pharm Sci. 2013;49(1):95-105.

7. Parodi F. Microwave heating and the acceleration of polymerization processes. In: Wlochowicz A (ed) Polymers and liquid crystals. Proceedings of SPIE - The International Society for Optical Engineering 4017, p 2(1999).

8. Bogdal D, Penczek P, Pielichowski J, Prociak A. Microwave assisted synthesis, crosslinking, and processing of polymeric materials. Adv Polym Sci. 2003, 163,193-263.

9. Singh V, Tiwari A, Tripathi DN, Sanghi R. Microwave assisted synthesis of guar-g-polyacrylamide. Carbohydr Polym. 2004;58:1-6.

10. Kaity S, Isaac J, Kumar PM, Bose A, Wong TW, Ghosh A. Microwave assisted synthesis of acrylamide graft ed locust bean gum and its application in drug delivery. Carbohydr Polym. 2013;98:1083-1094.

11. Berressem P. The birth of new delivery systems. Chem Br. 1999;35:29-32.

12. Adedokun MO, Ayorinde JO, Odeniyi MA. Compressional, mechanical and release properties of a novel gum in paracetamol tablet formulations. Curr Iss Pharm Med Sci. 2014;27:187-194.

13. Fell JT, Newton JM. Determination of tablet strength by diametrical compression test. J Pharm Sci. 1970; 59:688-691.

14. Kafedjiiski K, Werle M, Föger F, Bernkop-Schnürch A. Synthesis and in vitro characterization of a novel poly(acrylic acid)-glutathione conjugate. J Drug Del Sci Tech. 2005;15:411-417.

15. Emikpe BO, et al. Ex-vivo evaluation of the mucoadhesive properties of Cedrela odorata and Khaya senegalensis gums with possible applications for veterinary vaccine delivery. SpringerPlus. 2016;5:1289.

16. Adetunji AO, Odeniyi MA, Itiola OA. Characterisation and controlled release properties of Entandophragma angolense gum in ibuprofen matrix tablets. Farmacia. 2015;63:57-64.

17. Mokel J, Lippold B. Zero-order drug release from hydrocolloid matrices. Pharm Res. 1993;10:1066-1070.

18. Odeniyi MA, Khan HN, Peh KK. Release and mucoadhesion properties of diclofenac matrix tablets from natural and synthetic polymer blends. Acta Poloniae Pharmaceutica - Drug Res. 2015;72:559-567.

19. Costa P, Lobo JMS. Modeling and comparison of dissolution profiles. Eur J Pharm Sci. 2001;13:123-133.
20. Bakre LG, Jaiyeoba KT. Studies on the physicochemical properties of Abelmuscus esculentus L. (Okra) pods - a potential tablet excipient. Int J Biol Chem Sci. 2007;3,448-456.

21. Ayorinde JO, Odeniyi MA, Itiola OA. Evaluation of pharmaceutical and chemical equivalence of selected brands of diclofenac sodium tablets. East Central African J Pharm Sci. 2012;15:3-9.

22. Alebiowu G, Itiola OA. Effects of pregelatinization of starch binders on the interacting variables acting on the mechanical properties of a paracetamol tablet formulation. STP Pharm Sci. 2002;12:379-383.

23. British Pharmacopoeia (2010). Vol. 1. The Pharmaceutical Press, Her Majesty Stationery Office, London.

24. Bamiro OA, Owoduni AS, Bakre LG, Uwaezuoke OJ. Evaluation of Terminalia randii Baker F. gum as a disintegrant in paracetamol tablet formulation. J Chem Pharm Res. 2014;6:155-159.

25. Lawal MV, Odeniyi MA, Itiola OA. Effect of thermal and chemical modifications on the mechanical and release properties of paracetamol tablet formulations containing corn, cassava and sweet potato starches as filler-binders. Asian Pacific J Trop Biomed. 2015:5:576-580.

26. Alebiowu G, Adeagbo AA. Disintegrant properties of a paracetamol tablet formulation lubricated with co-processed lubricants. Farmacia. 2009;57:500-510. 